\title{
LETTER
}

\section{Burns to be alive: a complication of transcutaneous cardiac stimulation}

\author{
Xavier Muschart
}

External cardiac pacing devices (ECPDs) are commonly employed in emergency situations. The main indication for their use is untolerated bradycardia, especially in cases where other medical treatments have no effect [1]. Although the efficacy and safety of ECPDs are well documented, a classic side effect associated with their use is pain secondary to the electrically induced muscular contraction. Therefore, correct sedation-analgesia is critical for avoiding pain when reaching the correct voltages required for effective electrostimulation.

Here, we report the case of an 86-year-old patient with third-degree skin burns secondary to the use of an ECPD (a Zoll M Series Biphasic ${ }^{\bullet}$ defibrillator along with Stat Padz Multi-Function ${ }^{\circledR}$ adult electrodes with high viscosity polymer gel; Zoll Medical Corporation, USA) (Figure 1). To date, this observation represents the most serious ECPD-associated adult complication described in the literature.

Electric cardioversion, defibrillation or ECPDs saves lives [1]. In particular, external pacing is indicated for untolerated bradyarrhythmia where medications have no effect. Classic complications of transcutaneous cardiac stimulation are related to electricity [2]. Indeed, electricity can lead to accidental injury of the medical team via lack of precautions and iatrogenic skin burns. However, no ECPD-related skin burn has been described for adults in the literature $[3,4]$.

Although our patient benefited from the use of the ECPD, she acquired severe skin burns as a result of the treatment. Several possible explanations might explain this unusual complication. First of all, we cannot rule out that this issue resulted from a technical problem with the patch or glue. However, a poorly bonded patch or trapped air pockets between the gel and the skin could also be to blame. Additionally, greater impedance due to the breast weight of the patient could constitute a plausible explanation. Finally, the long wait time (2 hours) prior

Correspondence: xavier.muschart@uclouvain.be

CHU Dinant Godinne, UCL-NAMUR 1, av. Gaston Therasse, 5530 Yvoir, Belgium

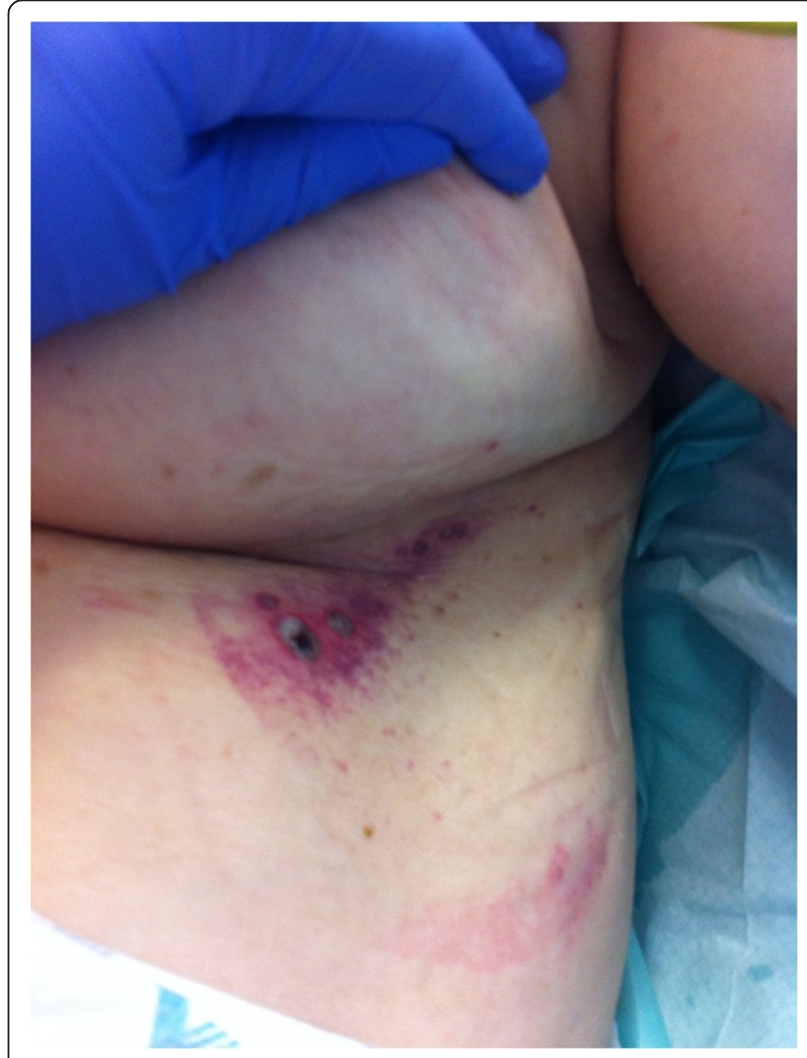

Figure 1 Two little third-degree skin burns under the breast following use of an external cardiac pacing device.

to placement of the internal pacing device might be a contributing factor.

Pain secondary to transcutaneous cardiac stimulation is usually due to electrically induced muscular contraction. Even though sedation-analgesia is indicated to prevent this common side effect, it can mask other complications. Skin burns must always be considered when patients continue to display pain under sedation-analgesia, especially in cases where the ECPD is used for a prolonged period of time. 


\section{Abbreviation}

ECPD: External cardiac pacing device.

\section{Competing interests}

The author declares that he had no competing interests.

\section{Acknowledgements}

Written informed consent for publication was provided by the patient and son; consent form is held by the author and the patient. Reviewing is possible (French version).

\section{Published online: 12 November 2014}

\section{References}

1. Deakin CD, Nolan JP, Sunde K, Koster RW: Electrical therapies: automated external defibrillators, defibrillation, cardioversion and pacing. Resuscitation 2010, 81:1293-1304.

2. Birkui P, Trigano JA, Degonde J: Then hemodynamic efficacy of transcutaneous cardiac stimulation. Bull Acad Natl Med 1990, 174:1361-1370. discussion 1370-1372.

3. Walund DC, Lynn AM, Hall DG: A third-degree burn associated with external cardiac pacing in a five-year-old boy. I Thorac Cardiovasc Surg 1992, 104:1754-1755.

4. Pride HB, McKinley DF: Third-degree burns from the use of an external cardiac pacing device. Crit Care Med 1990, 18:572-573.

doi:10.1186/s13054-014-0622-x

Cite this article as: Muschart: Burns to be alive: a complication of transcutaneous cardiac stimulation. Critical Care 2014 18:622. 